\title{
Impact of Thermal Oxidation on Morphological, Structural and Magnetic Properties of Fe-Ni Wire-Like Nanochains
}

\author{
MARCIN KRAJEWSKI, MATEUSZ TOKARCZYK, SABINA LEWIŃSKA, \\ KAMIL BOCHENEK, and ANNA ŚLAWSKA-WANIEWSKA
}

\begin{abstract}
This work presents the evolution of morphological, structural and magnetic properties of amorphous $\mathrm{Fe}-\mathrm{Ni}$ wire-like nanochains caused by thermal oxidation. The initial $\mathrm{Fe}_{1-x} \mathrm{Ni}_{x}$ samples $(x=0.75 ; 0.50 ; 0.25)$ were prepared through the magnetic-field-induced synthesis, and then they were heated in dry air at $400{ }^{\circ} \mathrm{C}$ and $500{ }^{\circ} \mathrm{C}$. These treatments led to two competing simultaneous processes occurring in the investigated samples, i.e., (i) a conversion of amorphous material into crystalline material, and (ii) their oxidation. Both of them strictly affected the morphological and structural properties of the Fe-Ni nanochains which, in turn, were associated with the amount of iron in material. It was found that the $\mathrm{Fe}_{0.75} \mathrm{Ni}_{0.25}$ and $\mathrm{Fe}_{0.50} \mathrm{Ni}_{0.50}$ nanochains were covered during thermal treatment by the nanoparticle oxides. This coverage did not constitute a good barrier against oxidation, and these samples became more oxidized than the $\mathrm{Fe}_{0.25} \mathrm{Ni}_{0.75}$ sample which was covered by oxide nanosheets and contained additional $\mathrm{Ni}_{3} \mathrm{~B}$ phase. The specific morphological evolutions of the $\mathrm{Fe}-\mathrm{Ni}$ nanochains also influenced their saturation magnetizations, whereas their coercivities did not vary significantly. The obtained results constitute an important source of information for future application of the thermally treated $\mathrm{Fe}-\mathrm{Ni}$ nanochains which could be applied in the energy storage devices or catalysis.
\end{abstract}

https://doi.org/10.1007/s11661-021-06326-1

(C) The Author(s) 2021

\section{INTRODUCTION}

THE conversion chemistry is a fast developing part of chemistry which describes the morphological changes of nanomaterials occurring during the chemical conversion reactions due to the formation of voids or hollows. ${ }^{[1]}$ In general, the conversion reactions less affect large bulk materials because the formation of voids or hollows possesses minor impact on their resulting properties. In turn, the formation of voids or hollows is very important at nanoscale where the material properties are extremely sensitive on changing their morphologies, shapes and/or sizes. ${ }^{[1,2]}$

Among conversion reactions, it is possible to distinguish three main types, namely: Kirkendall effect-driven processes, galvanic exchange, and anion exchange. ${ }^{[1]}$ All of them are associated with the intrinsic morphological

MARCIN KRAJEWSKI and KAMIL BOCHENEK are with the Institute of Fundamental Technological Research, Polish Academy of Sciences, Pawiéskiego 5B, 02-106 Warsaw, Poland. Contact e-mail: mkraj@ippt.pan.pl MATEUSZ TOKARCZYK is with the University of Warsaw, Faculty of Physics, Pasteura 5, 02-093 Warsaw, Poland. SABINA LEWINSKA and ANNA SLAWSKA-WANIEWSKA are with the Institute of Physics, Polish Academy of Sciences, Al. Lotników 32/46, 02-668 Warsaw, Poland.

Manuscript submitted February 1, 2021; accepted May 3, 2021.

Article published online May 25, 2021 changes which, in turn, are related to the autocatalytic interactions between nanomaterials and environment in which they are placed. Undoubtedly, the most common conversion reaction is the oxidation of metallic nanostructures. ${ }^{[3-9]}$ Typically, this process is very similar to the oxidation of bulk metal in which a very thin oxide shell is usually formed on the metal surface even at low temperatures. When the temperature increases, the rate of oxidation reaction is accelerated and this causes the growth of oxide layer thickness. At the same time, a formation of numerous small vacancies at the interface between metallic core and oxide shell is usually observed. If the vacancies are close each other, they condense in the form of voids. The increasing temperature or the increasing time of oxidation leads to the generation of more voids which coalesce and form hollows or even pores inside the material. In the case of nanomaterials, this phenomenon is often referred as the nanoscale Kirkendall effect and is associated with the fact that the outward diffusion of metal ions from the material core through the initially formed oxide layer is much faster than the inward diffusion of oxygen ions toward the core. ${ }^{[1,10]}$ Since the first description of the nanoscale Kirkendall effect in $2004{ }^{[11]}$ this process has become one of the most powerful synthesis strategies leading to the formation of hollow nanomaterials 
because it provides the possibility to obtain the uniquely tailored nanostructures such as core-shell, core-voidshell or even yolk-shell nanostructures. ${ }^{[1,3-8,10,12-17]}$

Considering that the diffusion coefficients of $\mathrm{Fe}$ and $\mathrm{Ni}$ ions through their own oxides are much higher than those of oxygen ions,${ }^{[10]}$ the nanostructures composed of these elements are very interesting materials in terms of their investigations associated with the nanoscale Kirkendall effect. Hence, there are some publications in the literature dealing with this matter. For instance, R. Nakamura et al. ${ }^{[12]}$ performed the advanced transmission electron microscopy (TEM) studies on the oxidized $\mathrm{Ni}$ nanoparticles (NPs) and they noticed that the condensation of vacancies into void during the oxidation process took place at an off-centered position. This observation was also confirmed for small oxidized $\mathrm{Ni}$ NPs with diameter of about $26 \mathrm{~nm}$ by Railsback et al. ${ }^{[4]}$ but, at the same time, they found that the oxidation of large Ni nanoparticles (diameter $\sim 96 \mathrm{~nm}$ ) resulted in the formation of porous NiO NPs possessing multiple voids. In turn, taking into account the oxidation of iron nanoparticles, it was found by several research groups that the void was typically formed at the center of nanoparticle. ${ }^{[13-17]}$ This observation has been more recently confirmed by Y.G. Sun et al. ${ }^{[6]}$ who carried out the oxidation process for the small colloidal Fe NPs (diameter of $13 \mathrm{~nm}$ ) and monitored their evolution using small-angle X-ray scattering (SAXS) and wide-angle X-ray scattering (WAXS). Based on the results coming from the synchrotron X-ray scattering techniques, they managed to simulate the process of oxidation and they compared those results to the images obtained from the high-resolution transmission electron microscope (HR-TEM). According to the observations of Y.G. Sun et al.,${ }^{[6]}$ the oxidation of Fe NPs followed the typical mechanism of vacancies formation and their coalescence into a void located at the center of nanoparticle.

Even if the oxidation of $\mathrm{Fe}$ and $\mathrm{Ni}$ nanomaterials is very interesting strategy to produce their hollow counterparts, most of recently published scientific works in this topic deal with their simplest form of nanomaterials, i.e., single metallic nanoparticles. To best of our knowledge, no paper describing the Kirkendall oxidation of the one-dimensional (1D) iron-nickel bimetallic nanostructures has been found, whereas only few papers about the impact of Kirkendall effect on thermally oxidized 1D Fe or Ni nanomaterials have been published so far. ${ }^{[18-22]}$ This is mainly associated with the fact that it is difficult to control the final dimensions and morphologies of the more complexed nanostructures during their synthesis. ${ }^{[22]}$ Nevertheless, some research group took an advantage of template-assisted methods and they investigated the influence of the nanoscale Kirkendall effect on the $\mathrm{Fe}$ and $\mathrm{Ni}$ wire-like nanostructures. The general conclusion coming from their works is that the total oxidation of metallic nanowires leads to the formation of metal oxide nanotubes. However, it has been also noticed that by playing the nanostructure sizes and process temperatures, it is possible to form the various segmented nanostructures, in particular, for the oxidation of $\mathrm{Ni}$ nanowires. ${ }^{[19-21]}$
As stated before, no publication associated with the impact of the thermal treatment on the 1D Fe-Ni nanostructures, which might be important material for sensors, catalysis, and microwave shielding absorbers, ${ }^{[2-26]}$ has been published so far. Therefore, this work presents for the first time how the oxidation of iron-nickel nanochains at $400{ }^{\circ} \mathrm{C}$ and $500{ }^{\circ} \mathrm{C}$ influences their chemical compositions as well as their structural, morphological and magnetic properties. Moreover, the results discussed in this paper can be considered as an important source of information for the future application of the thermally treated $\mathrm{Fe}-\mathrm{Ni}$ nanochains in the sector of energy storage or catalysis.

\section{EXPERIMENTAL}

\section{A. Fabrication of Iron-Nickel Wire-Like Nanostructures}

The $\mathrm{Fe}_{1-x} \mathrm{Ni}_{x}(x=0.75 ; 0.50 ; 0.25)$ wire-like nanochains were synthetized using so-called wet chemistry method which was proposed in one of our previous reports describing the MFI co-reduction reaction. ${ }^{[27]}$ In typical synthesis, the proper amounts of iron(II) chloride hydrate $\left(\mathrm{FeCl}_{2} \cdot x \mathrm{H}_{2} \mathrm{O} ; 98\right.$ pct, Carl Roth $\left.\mathrm{GmbH}\right)$ and nickel(II) chloride hexahydrate $\left(\mathrm{NiCl}_{2} \cdot 6 \mathrm{H}_{2} \mathrm{O} ; 97\right.$ pct, Carl Roth $\mathrm{GmbH}$ ) were dissolved in $300 \mathrm{ml}$ of deionized water. These mixtures served as the reaction precursors. In turn, $1.4 \mathrm{~g}$ of sodium borohydride $\left(\mathrm{NaBH}_{4} ; 97\right.$ pct, Carl Roth $\left.\mathrm{GmbH}\right)$ dissolved in 175 $\mathrm{ml}$ of deionized water was used as a reducing agent and was dropped to the previously prepared precursor solutions. The process was carried out in the inert argon gas (>99 pct, BialGaz Company) providing the inert atmosphere as well as stirring of reaction solution and also in the average external magnetic field of about 0.05 $\mathrm{T}$ induced by two parallel neodymium magnets.

The as-prepared nanomaterials were rinsed three times with ethanol (99.8 pct, Avantor $(\mathrm{POCH})$ ) and then three times with acetone $(99.5$ pct, Carl Roth $\mathrm{GmbH}$ ) in order to separate the pure powder products from other by-products. After that, they were dried at $50{ }^{\circ} \mathrm{C}$ in a vacuum for 2 hours. Such obtained Fe-Ni nanochains with various iron-to-nickel compositions acted as the initial materials for thermal oxidation investigations.

\section{B. Thermal Oxidation of Iron-Nickel Wire-Like Nanostructures}

The initially obtained $\mathrm{Fe}-\mathrm{Ni}$ nanochains with various iron-to-nickel compositions were subjected to a thermal oxidation processing which was performed in a tubular furnace. In general, each sample was separately heated in dry air at two different temperatures, i.e., at $400{ }^{\circ} \mathrm{C}$ and $500{ }^{\circ} \mathrm{C}$ for 0.5 hours. The process was carried out from room temperature with heating rate of $10{ }^{\circ} \mathrm{C}$ per minute. Then, the sample was gently cooling down to room temperature. At this point, it should be mentioned that these two temperatures have been chosen because of two factors, i.e., (i) they are not too high to sinter the $\mathrm{Fe}-\mathrm{Ni}$ nanochains, and (ii) this temperature range is 
crucial for the formation of various oxides, in particular, iron oxides. ${ }^{\text {[28] }}$

In order to facilitate the sample nomenclature, the $\mathrm{Fe}_{0.75} \mathrm{Ni}_{0.25}, \mathrm{Fe}_{0.50} \mathrm{Ni}_{0.50}$, and $\mathrm{Fe}_{0.25} \mathrm{Ni}_{0.75}$ nanochains treated at $400{ }^{\circ} \mathrm{C}$ and $500{ }^{\circ} \mathrm{C}$ are designated as $\mathrm{Fe}_{0.75} \mathrm{Ni}_{0.25} \quad 400{ }^{\circ} \mathrm{C}, \quad \mathrm{Fe}_{0.75} \mathrm{Ni}_{0.25} \quad 500{ }^{\circ} \mathrm{C}, \quad \mathrm{Fe}_{0.50} \mathrm{Ni}_{0.50}$ $400{ }^{\circ} \mathrm{C}, \mathrm{Fe}_{0.50} \mathrm{Ni}_{0.50} 500{ }^{\circ} \mathrm{C}, \mathrm{Fe}_{0.25} \mathrm{Ni}_{0.75} 400{ }^{\circ} \mathrm{C}$, and $\mathrm{Fe}_{0.25} \mathrm{Ni}_{0.75} 500{ }^{\circ} \mathrm{C}$.

\section{Characterization of Wire-Like Nanostructures}

The morphologies and structural properties of initially obtained and thermally treated Fe-Ni nanostructures were determined with a Zeiss Crossbeam 350 scanning electron microscope (SEM) equipped with an EDAX Elite Plus energy-dispersive X-ray spectrometer (EDS), a JEOL - JEM 1011 transmission electron microscope (TEM) and a JEOL JEM 2100 FEG transmission electron microscope (TEM) equipped with an Oxford EDS and a Gatan Image Filter (GIF, Tridiem 863 linked with electron energy loss spectrometer (EELS) function), a Phillips X'Pert Diffractometer (XRD) equipped with a $\mathrm{Cu}$ X-ray lamp, and a Renishaw inVia confocal Raman spectrometer (RS) equipped with a charge-coupled device camera and a Nd-YAG laser $(\lambda$ $=532 \mathrm{~nm}$ ) of continuous wave excitation. The susceptibility to oxidation of the as-prepared Fe-Ni samples was examined with a thermogravimetric analysis (TGA) technique performed with a Mettler Toledo TGA/ DSC3 + analyzer. Moreover, these investigations were carried in dry air purged with $30 \mathrm{~mL} \mathrm{~min}^{-1}$ of argon and in the temperature range between $30^{\circ} \mathrm{C}$ and $1000{ }^{\circ} \mathrm{C}$ with heating rate $10 \mathrm{deg}$ per minute. In turn, the magnetic properties of initially formed as well as thermally treated nanochains were analyzed at room temperature with a Quantum Design Physical Property Measurement System equipped with a VSM option.

\section{RESULTS AND DISCUSSION}

The morphologies of as-prepared as well as thermally treated iron-nickel nanomaterials have been observed with SEM, and the collected images are shown in Figure 1. According to the presented results, the as-prepared $\mathrm{Fe}-\mathrm{Ni}$ nanostructures with all investigated chemical compositions look like long straight wires, whereas analyzing the SEM images of the thermally treated samples it is hardly difficult to observe whether they reveal the wire-like structures. Their morphologies vary depending on their initial chemical composition and the applied temperature during oxidation processing. This, indeed, proves that their morphologies evolve with increasing temperatures. Moreover, it is evident that the $\mathrm{Fe}_{0.75} \mathrm{Ni}_{0.25}$ and $\mathrm{Fe}_{0.50} \mathrm{Ni}_{0.50}$ nanochains treated at $500{ }^{\circ} \mathrm{C}$ are charged (cf. Figures $1(\mathrm{~g})$ and $(\mathrm{h})$ ). This indicates that the surfaces of these samples are composed of less conductive material than other samples.

The chemical composition of the as-prepared Fe-Ni samples was studied with the EDS technique in parallel to the SEM measurements. The obtained results are placed in Table I. In general, the areal EDS data have been collected from the investigated materials sticked to a carbon tape covering an aluminum holder. This has caused that each sample reveals the quite intense signal related to carbon. Moreover, the elemental contribution associated with boron and oxygen in the samples may be disturbed by the carbon tape. Nevertheless, the obtained EDS results measured for the as-prepared Fe-Ni samples indicate that they are partially contaminated by the compounds containing boron and sodium. They might be the unreacted $\mathrm{NaBH}_{4}$ taken to the synthesis or by-products of process, for instance, $\mathrm{B}(\mathrm{OH})_{3}$. Also, it cannot be excluded that some of boron form the borides with the iron, nickel or both these elements. Such observations have been already reported for the $\mathrm{Ni}$ nanoparticles ${ }^{[29]}$ as well as the Fe nanoparticles. ${ }^{[30]}$ The EDS investigations show that the as-prepared Fe-Ni nanochains can be partly oxidized due to the presence of oxygen whose content is higher than the previously recalled boron, sodium and carbon. At the same time, the EDS data confirm that the purification process has led to the complete removal of chloride ions from the samples. Finally, it should be noted that the actual share between $\mathrm{Fe}$ and $\mathrm{Ni}$ atoms in the as-prepared $\mathrm{Fe}-\mathrm{Ni}$ nanochains corresponds well to the composition of initial ion precursors taken to the MFI synthesis.

In order to precisely determine the characteristic morphological and structural features of as-prepared and thermally treated samples, the TEM measurements have been performed and the obtained results are shown in Figure 2. Analyzing the collected images, one can see that all as-prepared Fe-Ni nanochains are very similar in terms of their building. Namely, they are composed of nanoparticles which are aligned in the nearly straight lines. Moreover, each sample reveals so-called core-shell structure in which a dark core region and a thin light-gray shell layer are clearly perceivable. In general, the presence of shell layer is associated with an initial oxidation of material and this is a typical phenomenon for the nanomaterials consisted of iron and/or nickel which stay in contact with atmospheric air. The formation of oxide layer has been confirmed by the EELS elemental mapping recorded for the single as-prepared $\mathrm{Fe}_{0.50} \mathrm{Ni}_{0.50}$ nanochain (cf. Figure A1). This experiment clearly indicates that the core of nanochain is filled by a mixture of $\mathrm{Fe}$ and $\mathrm{Ni}$, whereas the shell contains a significant amount of oxygen. Moreover, the presented EELS data prove that the shell layer is quite homogeneous and adheres well to the material core. Its thickness measured for all as-prepared $\mathrm{Fe}-\mathrm{Ni}$ nanochains does not exceed $4 \mathrm{~nm}$ which is a typical value for iron and nickel nanoparticles. ${ }^{[15,29-32]}$ In turn, the TEM images of the thermally treated Fe-Ni nanochains indicate that these samples still reveal the wire-like structures which has been difficult to observe with SEM. It is also clearly visible that their morphologies depend on their initial chemical composition, their purity, and the applied temperature during oxidation processing. For instance, in the case of $\mathrm{Fe}_{0.75} \mathrm{Ni}_{0.25}$ chains the oxidation at $400{ }^{\circ} \mathrm{C}$ causes irregular thickening of oxide shell and simultaneous decreasing of core amount. In turn, the increase in temperature to $500{ }^{\circ} \mathrm{C}$ leads to a roughening of surface layer due to the formation of nanoparticles as well as to 

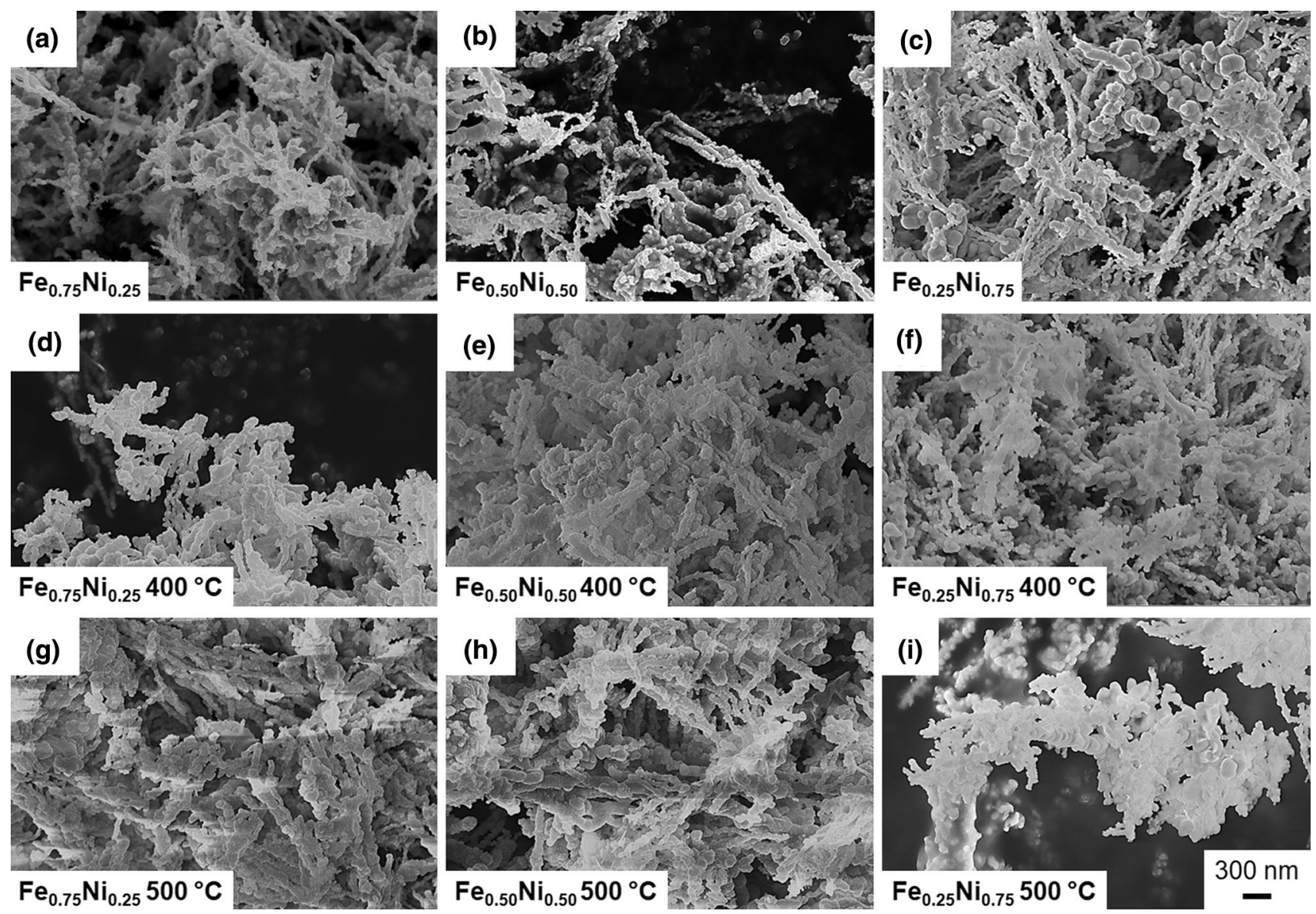

Fig. 1-SEM images of as-prepared (a) $\mathrm{Fe}_{0.75} \mathrm{Ni}_{0.25},(b) \mathrm{Fe}_{0.50} \mathrm{Ni}_{0.50},(c) \mathrm{Fe}_{0.25} \mathrm{Ni}_{0.75}$ nanochains as well as thermally treated (d) $\mathrm{Fe}_{0.75} \mathrm{Ni}_{0.25},(e)$ $\mathrm{Fe}_{0.50} \mathrm{Ni}_{0.50}$, (f) $\mathrm{Fe}_{0.25} \mathrm{Ni}_{0.75}$ nanochains at $400{ }^{\circ} \mathrm{C}$, and $(g) \mathrm{Fe}_{0.75} \mathrm{Ni}_{0.25}$, (h) $\mathrm{Fe}_{0.50} \mathrm{Ni}_{0.50},(i) \mathrm{Fe}_{0.25} \mathrm{Ni}_{0.75}$ nanochains at $500{ }^{\circ} \mathrm{C}$; the scale bar shown in the image of (i) is also valid for other images.

a formation of hollow spaces inside the structure (cf. Figure A2(a)). For the sample with $\mathrm{Fe}_{0.50} \mathrm{Ni}_{0.50}$ composition, the growth of nanoparticles on the surface layer begins with a thickening of oxide shell at lower temperature, i.e., $400{ }^{\circ} \mathrm{C}$, whereas the treatment at $500{ }^{\circ} \mathrm{C}$ causes a formation of more nanoparticles as well as a roughening of previously and newly formed nanoparticles. At the same time, a lot of empty spaces are formed in the interior structure of $\mathrm{Fe}_{0.50} \mathrm{Ni}_{0.50}$ chains (cf. Figure A2(b)). It is also interesting that the nanoparticles forming on the $\mathrm{Fe}_{0.75} \mathrm{Ni}_{0.25}$ and $\mathrm{Fe}_{0.50} \mathrm{Ni}_{0.50}$ samples tend to grow on their initial oxide layers (cf. Figure A2(c)). This again confirms that the initial shells adhere well to the material cores. In comparison with two samples discussed before, the sample with $\mathrm{Fe}_{0.25} \mathrm{Ni}_{0.75}$ composition behaves in different manner during oxidation process. Namely, the treatment at $400{ }^{\circ} \mathrm{C}$ causes the transformation of initial oxide shell into a kind of oxide sheets covering the core, whereas the increase in temperature to $500{ }^{\circ} \mathrm{C}$ seems not to change the morphology obtained at $400{ }^{\circ} \mathrm{C}$. This observation might be related to the contamination of the $\mathrm{Fe}_{0.25} \mathrm{Ni}_{0.75}$ nanochains which has been proven in the previously discussed EDS results. Besides that, it is worth adding that only this sample does not reveal the presence of hollows which frequently appear at elevated temperatures and are associated the nanoscale Kirkendall effect. . $^{[3-8,10,11,14]}$ Therefore, it is assumed that among the investigated $\mathrm{Fe}-\mathrm{Ni}$ nanochains the nanomaterial with $\mathrm{Fe}_{0.25} \mathrm{Ni}_{0.75}$ composition is the most resistance against oxidation at temperatures up to $500{ }^{\circ} \mathrm{C}$.

As stated above, the TEM measurements indicate that the thermally treated $\mathrm{Fe}-\mathrm{Ni}$ samples possess very developed surface area covered by either nanoparticles or nanosheets. This, in turn, hinders the characterization of their morphological features using the SEM technique, in particular, when the chains lay close each other. Moreover, the TEM observations show that the as-prepared $\mathrm{Fe}-\mathrm{Ni}$ nanochains are very irregular in terms of their diameters because they are composed of nanoparticles with various diameters ranging from 20 to $140 \mathrm{~nm}$. This causes that even diameter of a single chain may vary. Taking into account this specific feature of material, we do not provide in our work the precise values of diameters for as-prepared as well as thermally treated $\mathrm{Fe}-\mathrm{Ni}$ nanochains. Nevertheless, it is worth noting that the mean diameters for $\mathrm{Fe}_{0.75} \mathrm{Ni}_{0.25}$ and $\mathrm{Fe}_{0.50} \mathrm{Ni}_{0.50}$ samples are more or less similar, whereas the average diameter for $\mathrm{Fe}_{0.25} \mathrm{Ni}_{0.75}$ nanochains is about 10 nm lower than that for $\mathrm{Fe}_{0.75} \mathrm{Ni}_{0.25}$ and $\mathrm{Fe}_{0.50} \mathrm{Ni}_{0.50}$ nanostructures. In turn, the average diameter of nanoparticles grown on the $\mathrm{Fe}_{0.75} \mathrm{Ni}_{0.25}$ as well as 
Table I. Weight and Atomic Percentage of Elements Forming the As-Prepared $\mathrm{Fe}_{0.75} \mathrm{Ni}_{0.25}, \mathrm{Fe}_{0.50} \mathrm{Ni}_{0.50}, \mathrm{Fe}_{0.25} \mathrm{Ni}_{0.75} \mathrm{Nanochains}$ and Carbon Type Determined With EDS Technique

\begin{tabular}{llcccc}
\hline Element & \multicolumn{1}{c}{ Percentage } & $\mathrm{Fe}_{0.75} \mathrm{Ni}_{0.25}$ & $\mathrm{Fe}_{0.50} \mathrm{Ni}_{0.50}$ & $\mathrm{Fe}_{0.25} \mathrm{Ni}_{0.75}$ & Carbon Tape \\
\hline $\mathrm{B}$ & weight & 3.23 & 1.92 & 4.33 & 0.30 \\
$\mathrm{C}$ & atomic & 8.99 & 7.03 & 13.43 & 0.30 \\
$\mathrm{O}$ & weight & 8.18 & 1.42 & 5.65 & 94.60 \\
$\mathrm{O}$ & atomic & 20.40 & 4.69 & 15.76 & 5.80 \\
& weight & 15.96 & 9.31 & 9.58 & 3.80 \\
$\mathrm{Na}$ & atomic & 29.80 & 23.75 & 20.10 & - \\
$\mathrm{Fe}$ & weight & 2.83 & 1.82 & 4.33 & - \\
$\mathrm{Ni}$ & atomic & 3.74 & 3.26 & 6.36 & - \\
$\mathrm{Fe}$ & weight & 54.44 & 48.18 & 17.14 & - \\
$\mathrm{Femic}$ & weight & 15.19 & 35.27 & 10.40 & - \\
$\mathrm{Ni}$ & atomic & 7.88 & 37.35 & 58.97 & - \\
& normalized weight* & 78.00 & 25.99 & 33.94 & - \\
\hline
\end{tabular}

* The values of normalized weight and atomic percentage of $\mathrm{Fe}$ and $\mathrm{Ni}$ elements were determined considering the EDS signal associated with them and avoiding the signal of other elements.
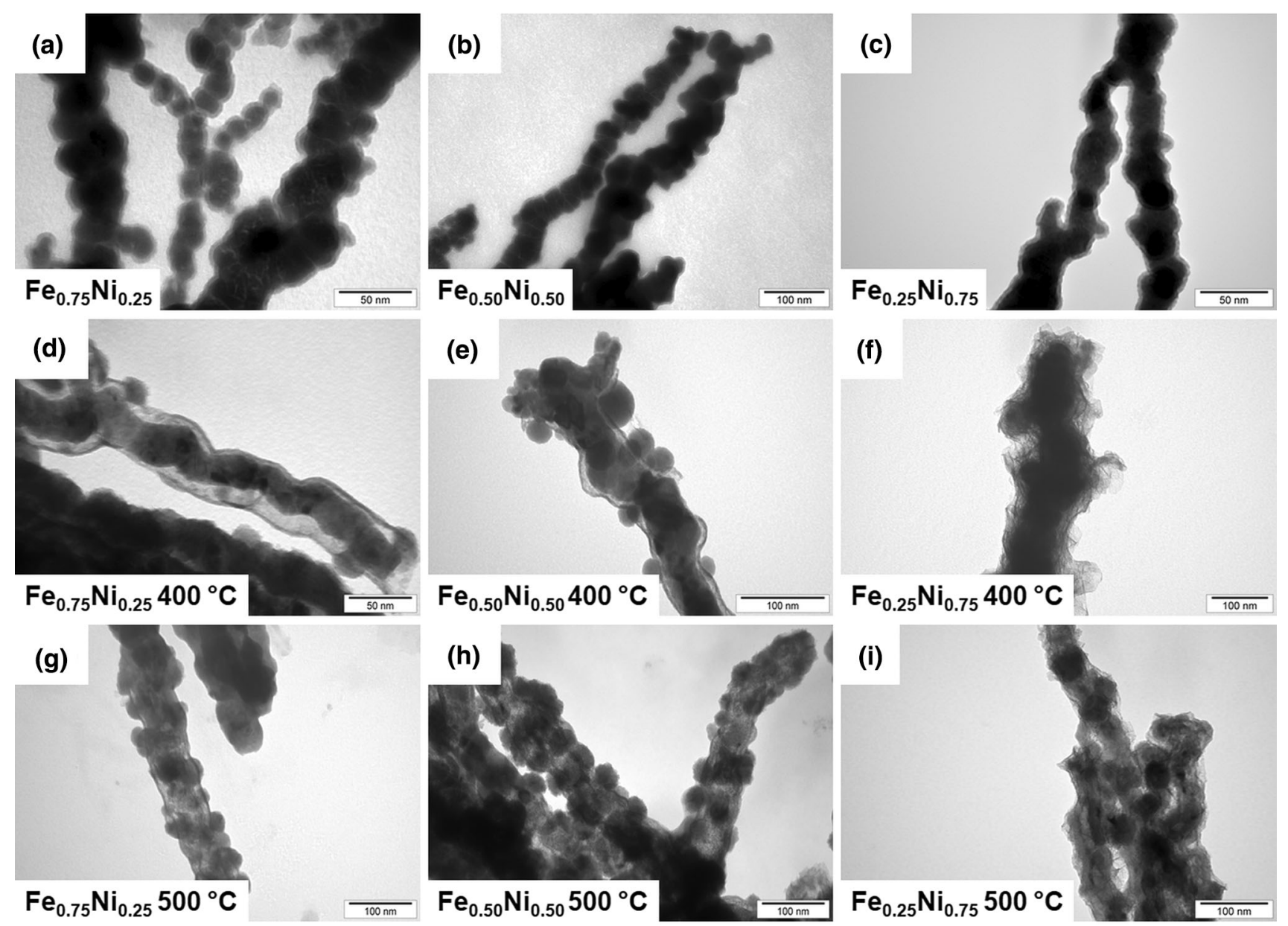

Fig. 2-TEM images of as-prepared (a) $\mathrm{Fe}_{0.75} \mathrm{Ni}_{0.25}$, (b) $\mathrm{Fe}_{0.50} \mathrm{Ni}_{0.50}$, (c) $\mathrm{Fe}_{0.25} \mathrm{Ni}_{0.75}$ nanochains as well as thermally treated (d) $\mathrm{Fe}_{0.75} \mathrm{Ni}_{0.25},(e)$ $\mathrm{Fe}_{0.50} \mathrm{Ni}_{0.50},(f) \mathrm{Fe}_{0.25} \mathrm{Ni}_{0.75}$ nanochains at $400{ }^{\circ} \mathrm{C}$, and $(g) \mathrm{Fe}_{0.75} \mathrm{Ni}_{0.25},(h) \mathrm{Fe}_{0.50} \mathrm{Ni}_{0.50},(i) \mathrm{Fe}_{0.25} \mathrm{Ni}_{0.75}$ nanochains at $500{ }^{\circ} \mathrm{C}$. 
$\mathrm{Fe}_{0.50} \mathrm{Ni}_{0.50}$ nanochains during the oxidation at $500{ }^{\circ} \mathrm{C}$ is quite uniform and they equal about $24 \mathrm{~nm}$. It is also observed that the thermal treatment does not influence the lengths of $\mathrm{Fe}-\mathrm{Ni}$ nanochains.

The structural transformations occurring in the $\mathrm{Fe}-\mathrm{Ni}$ nanochains during the thermal oxidation have been monitored with two complementary techniques, i.e., XRD and RS, and the obtained results are shown in Figure 3 and Figure 4, respectively. At this point, it should be stated that the angle positions of XRD patterns have been matched with the phases presented in the oxidized Fe-Ni nanochains based on the JCPDS database. The presence of bcc $\mathrm{Fe}-\mathrm{Ni}$, fcc $\mathrm{Fe}-\mathrm{Ni}$, $\mathrm{NiFe}_{2} \mathrm{O}_{4}$ (nickel ferrite), $\mathrm{Fe}_{3} \mathrm{O}_{4}$ (magnetite), $\alpha-\mathrm{Fe}_{2} \mathrm{O}_{3}$ (hematite), and $\mathrm{Ni}_{3} \mathrm{~B}$ (nickel boride) has been determined according to the following JCPDS card 37-0474, $47-1417,82-8103,87-2334,87-1166$, and 82-1699, respectively. In turn, the positions of characteristic bands and corresponding vibrational modes for oxides presented in the oxidized Fe-Ni nanochains have been identified based on literature and they are collected in Table II. ${ }^{[33-37]}$ Returning to the presented data, one can see that all as-prepared $\mathrm{Fe}-\mathrm{Ni}$ nanochains reveal amorphous character because only two weak and broad diffraction peaks are visible in their XRD spectra. More detailed analysis confirming this assumption has been previously discussed. ${ }^{[27]}$ In turn, the thermal treatment at $400{ }^{\circ} \mathrm{C}$ and $500{ }^{\circ} \mathrm{C}$ is associated with two competing processes, i.e., (i) a conversion of amorphous material into crystalline material, and (ii) its oxidation. It is well known that various amorphous inorganic materials are frequently subjected to the thermal treatment in order to improve their crystallinity. ${ }^{[1,22,33,38,40]}$ At the same time, the iron-containing materials suffer from the oxidation because iron as the element tends to be imminently bound with oxygen coming from the atmosphere even at room temperature. ${ }^{[7,13-16,28,32]}$ Thus, it is clear that the susceptibility to oxidation of the investigated $\mathrm{Fe}-\mathrm{Ni}$ nanochains is linked with the amount of iron inside them and detailed analysis of the obtained XRD and RS data confirms this assumption. Namely, in the case of the $\mathrm{Fe}_{0.75} \mathrm{Ni}_{0.25}$ chains the thermal treatment at $400{ }^{\circ} \mathrm{C}$ causes their crystallization in a form of bcc Fe-Ni as well as their advanced oxidation. In general, the presence of a mixture of $\mathrm{NiFe}_{2} \mathrm{O}_{4}, \mathrm{Fe}_{3} \mathrm{O}_{4}$, and $\alpha-\mathrm{Fe}_{2} \mathrm{O}_{3}$ has been detected with both XRD and RS techniques. Nevertheless, the peak intensities of XRD for Fe-Ni alloy are much higher than that referred to oxides. This indicates that the thermal treatment at $400{ }^{\circ} \mathrm{C}$ is not sufficient to oxidize whole nanomaterial. Moreover, the characteristic Raman bands associated with abovementioned oxides are not well developed at this temperature because they are quite broad and low intense. In turn, the thermal processing at $500{ }^{\circ} \mathrm{C}$ of the $\mathrm{Fe}_{0.75} \mathrm{Ni}_{0.25}$ chains leads to their significant oxidation. This is related to the fact that the intensities of the XRD peaks corresponding to bcc Fe-Ni are greatly weaker than that of oxides. Besides that, they are not easily seen because they hide in the arms of oxides peaks causing their broadening. Comparing the XRD and Raman measurements for the $\mathrm{Fe}_{0.75} \mathrm{Ni}_{0.25} 500{ }^{\circ} \mathrm{C}$, it is evident that the dominant oxide phase in this sample is hematite but two other phases related to $\mathrm{NiFe}_{2} \mathrm{O}_{4}$ and $\mathrm{Fe}_{3} \mathrm{O}_{4}$ are also present but their share is greatly lower than that of $\alpha-\mathrm{Fe}_{2} \mathrm{O}_{3}$. Considering the oxidation of the $\mathrm{Fe}_{0.50} \mathrm{Ni}_{0.50}$ sample, one can see that among two competing processes the conversion of amorphous $\mathrm{Fe}_{0.50} \mathrm{Ni}_{0.50}$ phase into crystalline one slightly prevails over the oxidation of this material. This observation is due to two facts, namely: (i) the XRD peaks for oxides are much less intense than those related to the $\mathrm{Fe}-\mathrm{Ni}$ phase, and (ii) the RS spectra of the oxidized $\mathrm{Fe}_{0.50} \mathrm{Ni}_{0.50}$ samples are much noisier than that recorded for the oxidized $\mathrm{Fe}_{0.75} \mathrm{Ni}_{0.25}$ chains. It should be also pointed out that in a contrary to the $\mathrm{Fe}_{0.75} \mathrm{Ni}_{0.25}$ sample the amorphous $\mathrm{Fe}_{0.50} \mathrm{Ni}_{0.50}$ chains convert into fcc $\mathrm{Fe}-\mathrm{Ni}$ phase under the thermal processing and the XRD peaks referred to this phase are well visible for sample oxidized at $400{ }^{\circ} \mathrm{C}$ as well as $500{ }^{\circ} \mathrm{C}$. Furthermore, the thermal treatment of the $\mathrm{Fe}_{0.50} \mathrm{Ni}_{0.50}$ chains at $400{ }^{\circ} \mathrm{C}$ results in the formation of a mixture of $\mathrm{NiFe}_{2} \mathrm{O}_{4}$ and $\mathrm{Fe}_{3} \mathrm{O}_{4}$, whereas the process at $500{ }^{\circ} \mathrm{C}$ additionally causes the partial conversion of $\mathrm{Fe}_{3} \mathrm{O}_{4}$ into $\alpha-\mathrm{Fe}_{2} \mathrm{O}_{3}$. However, the level of magnetite oxidation is not too high. This observation, in fact, can be explained by the Raman spectrum of $\mathrm{Fe}_{0.50} \mathrm{Ni}_{0.50} 500{ }^{\circ} \mathrm{C}$ which does not reveal well-developed

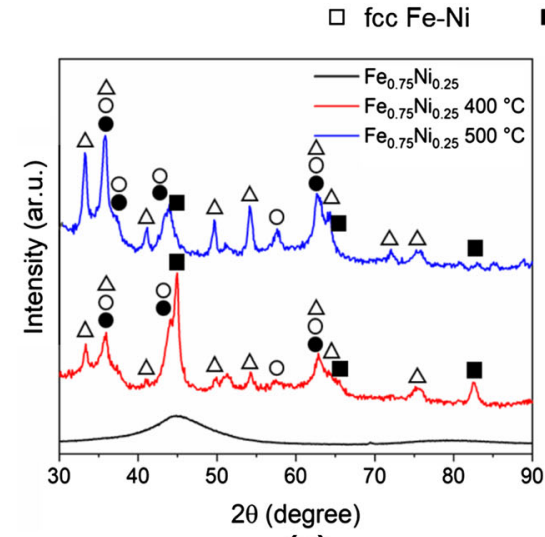

(a)

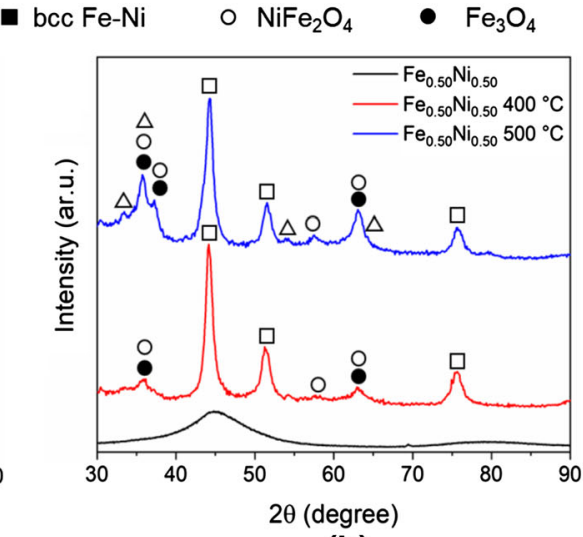

(b) $\triangle \alpha-\mathrm{Fe}_{2} \mathrm{O}_{3}$

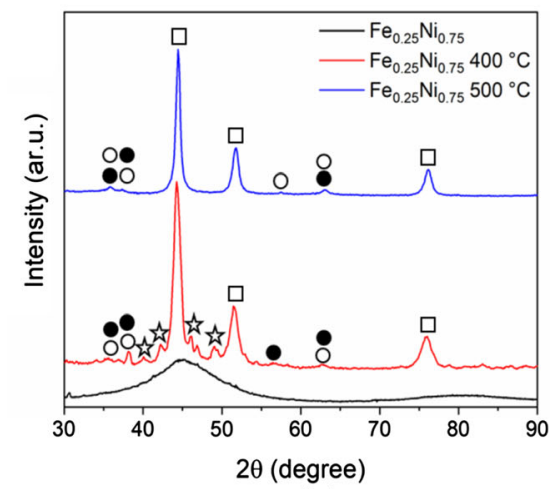

(c)

Fig. 3-XRD patterns of as-prepared and thermally treated (a) $\mathrm{Fe}_{0.75} \mathrm{Ni}_{0.25}$, (b) $\mathrm{Fe}_{0.50} \mathrm{Ni}_{0.50}$, (c) $\mathrm{Fe}_{0.25} \mathrm{Ni}_{0.75}$ nanochains. 


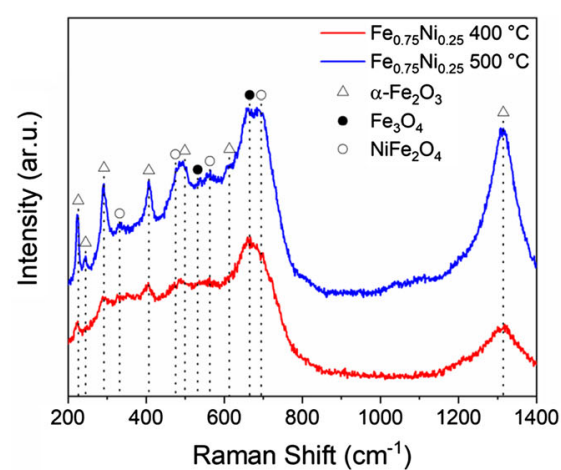

(a)

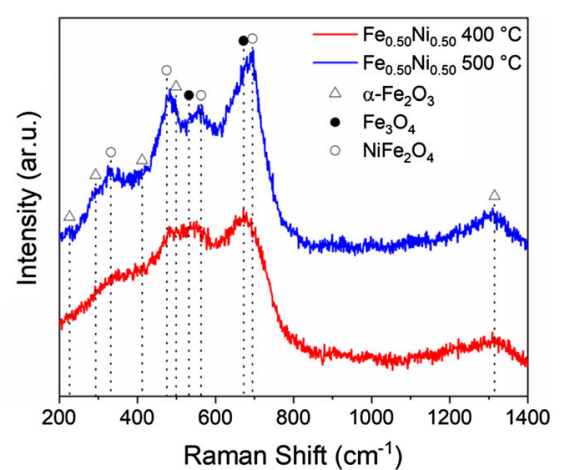

(b)

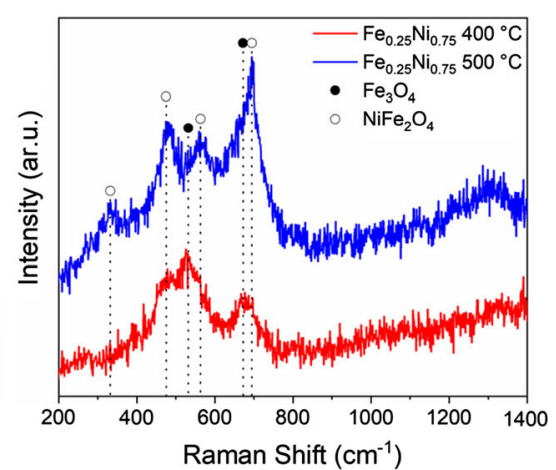

(c)

Fig. 4 - Raman spectra of as-prepared and thermally treated (a) $\mathrm{Fe}_{0.75} \mathrm{Ni}_{0.25}$, (b) $\mathrm{Fe}_{0.50} \mathrm{Ni}_{0.50},(c) \mathrm{Fe}_{0.25} \mathrm{Ni}_{0.75}$ nanochains.

Table II. Characteristic Raman Bands and Corresponding Vibrational Modes for Oxides Presented in the Oxidized Fe-Ni Nanochains

\begin{tabular}{ll}
\hline Oxide & \multicolumn{1}{c}{ Raman Vibrational Modes (Wavenumbers) } \\
\hline $\mathrm{NiFe}_{2} \mathrm{O}_{4}$ & $E_{\mathrm{g}}\left(332 \mathrm{~cm}^{-1}\right) ; T_{2 \mathrm{~g}}\left(475 \mathrm{~cm}^{-1}\right) ; T_{2 \mathrm{~g}}\left(563 \mathrm{~cm}^{-1}\right) ; A_{1 \mathrm{~g}}\left(695 \mathrm{~cm}^{-1}\right)$ \\
$\mathrm{Fe}_{3} \mathrm{O}_{4}$ & $T_{2 \mathrm{~g}}\left(532 \mathrm{~cm}^{-1}\right) ; A_{1 \mathrm{~g}}\left(662 \mathrm{~cm}^{-1}\right)$ \\
$\alpha-\mathrm{Fe}_{2} \mathrm{O}_{3}$ & $A_{1 \mathrm{~g}}\left(226 \mathrm{~cm}^{-1}\right) ; E_{\mathrm{g}}\left(245 \mathrm{~cm}^{-1}\right) ; E_{\mathrm{g}}\left(292 \mathrm{~cm}^{-1}\right) ; E_{\mathrm{g}}\left(407 \mathrm{~cm}^{-1}\right) ; A_{1 \mathrm{~g}}$ \\
& $\left(499 \mathrm{~cm}^{-1}\right) ; E_{\mathrm{g}}\left(613 \mathrm{~cm}^{-1}\right) ; 2 \mathrm{LO}\left(1315 \mathrm{~cm}^{-1}\right)$ \\
\hline
\end{tabular}

characteristic bands typically located at 226, 245, 292, 407, and $613 \mathrm{~cm}^{-1}$. Finally, the $\mathrm{Fe}_{0.25} \mathrm{Ni}_{0.75}$ sample seems to be the most resistant for oxidation at $400{ }^{\circ} \mathrm{C}$ and $500{ }^{\circ} \mathrm{C}$ among all investigated Fe-Ni chains. This is associated with two interrelated facts. The first one has been pointed out before, and it is linked with that the surface of this sample is well covered by oxide nanosheets which constitute better barrier against oxidation than oxide nanoparticles formed in the case of $\mathrm{Fe}_{0.75} \mathrm{Ni}_{0.25}$ and $\mathrm{Fe}_{0.50} \mathrm{Ni}_{0.50}$ chains. In turn, the second reason is directly related to the structural properties. Namely, it should be noticed that the XRD pattern of the $\mathrm{Fe}_{0.25} \mathrm{Ni}_{0.75} 400{ }^{\circ} \mathrm{C}$ reveals some weak peaks visible at the $2 \theta$ position ranging between 40 and $50 \mathrm{deg}$. In fact, these XRD peaks have not been observed in any of previously discussed samples. Their origin is associated with the presence of $\mathrm{Ni}_{3} \mathrm{~B}$ phase which is frequently formed during the synthesis of nickel compounds in the reduction reaction with a reducing agent containing $\mathrm{BH}_{4}^{-}$ions. ${ }^{[41-43]}$ Also, it has been already proven that the $\mathrm{Ni}_{3} \mathrm{~B}$ is more resistant against oxidation than a pure metallic material. ${ }^{[42]}$ Therefore, it might be that the presence of $\mathrm{Ni}_{3} \mathrm{~B}$ phase in the $\mathrm{Fe}_{0.25} \mathrm{Ni}_{0.75}$ sample treated at $400{ }^{\circ} \mathrm{C}$ hinders its thermal oxidation. At this point, it should be explained that no bands apart from those for nickel ferrite and magnetite are found during the RS measurements because this method mainly collects signal from sample surface, whereas the $\mathrm{Ni}_{3} \mathrm{~B}$ phase is rather presented in the core of $\mathrm{Fe}_{0.25} \mathrm{Ni}_{0.75}$ chains. This agrees well with the highest amount of boron detected during the EDS measurement among all as-prepared samples. It is also interesting that the XRD peaks referred to the $\mathrm{Ni}_{3} \mathrm{~B}$ phase seem to disappear for the $\mathrm{Fe}_{0.25} \mathrm{Ni}_{0.75} 500{ }^{\circ} \mathrm{C}$. This observation, indeed, is in a good agreement with the previously reported crystallization of the $\mathrm{Ni}_{3} \mathrm{~B}$ nanoparticles in which the thermal annealing at about $450{ }^{\circ} \mathrm{C}$ has resulted in the formation of boron-containing nickel nanoparticles. ${ }^{[41-43]}$ Further analysis of the XRD results indicates that the thermally treated $\mathrm{Fe}_{0.25} \mathrm{Ni}_{0.75}$ chains convert into fcc $\mathrm{Fe}-\mathrm{Ni}$ phase similarly like the $\mathrm{Fe}_{0.50} \mathrm{Ni}_{0.50}$ sample. They are also slightly oxidized because the weak signal coming from a mixture of $\mathrm{NiFe}_{2} \mathrm{O}_{4}$ and $\mathrm{Fe}_{3} \mathrm{O}_{4}$ is detected for the $\mathrm{Fe}_{0.25} \mathrm{Ni}_{0.75}$ chains treated at $400{ }^{\circ} \mathrm{C}$ and $500{ }^{\circ} \mathrm{C}$ with both XRD and RS techniques. Nevertheless, it is important to point out that the relative $\mathrm{XRD}$ and $\mathrm{RS}$ intensities referred to oxides are a bit higher for the $\mathrm{Fe}_{0.25} \mathrm{Ni}_{0.75} 500{ }^{\circ} \mathrm{C}$.

In order to clarify the different resistance against oxidation of the as-prepared Fe-Ni chains, the thermogravimetric analysis (TGA) measurements have been performed in dry air purged with $30 \mathrm{~mL} \mathrm{~min}^{-1}$ of argon and the obtained results are shown in Figure 5. The solid lines in this figure represent the data collected up to $500{ }^{\circ} \mathrm{C}$, whereas the dashed lines above $500{ }^{\circ} \mathrm{C}$. Analyzing them, one can see that the mass of all as-prepared $\mathrm{Fe}-\mathrm{Ni}$ samples slightly fades up to about $150{ }^{\circ} \mathrm{C}$ due to the desorption of moisture and then increases due to the reaction with oxygen coming from experimental environment. The oxidation of the $\mathrm{Fe}_{0.75} \mathrm{Ni}_{0.25}$ and $\mathrm{Fe}_{0.50} \mathrm{Ni}_{0.50}$ chains begins at around $200{ }^{\circ} \mathrm{C}$. Nevertheless, it should be noted that this process is much more intense and faster for the $\mathrm{Fe}_{0.75} \mathrm{Ni}_{0.25}$ sample. In addition, the shape of the TGA curve recorded for this sample suggests that it is fully oxidized at temperature of $600{ }^{\circ} \mathrm{C}$, whereas the oxidation of the $\mathrm{Fe}_{0.50} \mathrm{Ni}_{0.50}$ chains is not completed even at $1000{ }^{\circ} \mathrm{C}$. In turn, the oxidation of the $\mathrm{Fe}_{0.25} \mathrm{Ni}_{0.75}$ sample initiates at $400{ }^{\circ} \mathrm{C}$ and similarly to the $\mathrm{Fe}_{0.50} \mathrm{Ni}_{0.50}$ chains this process is not finished at $1000{ }^{\circ} \mathrm{C}$. Regardless of the heating 
temperature, the highest gain of mass is observed for the $\mathrm{Fe}_{0.75} \mathrm{Ni}_{0.25}$ chains and it equals 13,22 , and 31 pct of the initial mass at $400{ }^{\circ} \mathrm{C}, 500{ }^{\circ} \mathrm{C}$, and $1000{ }^{\circ} \mathrm{C}$, respectively. Considering the $\mathrm{Fe}_{0.50} \mathrm{Ni}_{0.50}$ sample, the increase in weight equals 2,7 , and 18 pct with regard to the initial mass measured at 400,500 , and $1000{ }^{\circ} \mathrm{C}$, respectively. The lowest gain of mass is found for the sample with $\mathrm{Fe}_{0.25} \mathrm{Ni}_{0.75}$ composition and it reaches 3 and 14 pet at 500 and $1000{ }^{\circ} \mathrm{C}$, respectively. The above-presented TGA data supplement well the structural investigations discussed before and confirm the previous assumption that the more iron inside in the as-prepared Fe-Ni nanochains the more susceptible to thermal oxidation they are.

The magnetic hysteresis curves of as-prepared and thermally treated $\mathrm{Fe}-\mathrm{Ni}$ chains have been recorded at room temperature, and they are shown in Figure 6. Analyzing them, one can see that all investigated samples reveal the ferromagnetic character. It is also evident that the thermal treatment of the Fe-Ni chains

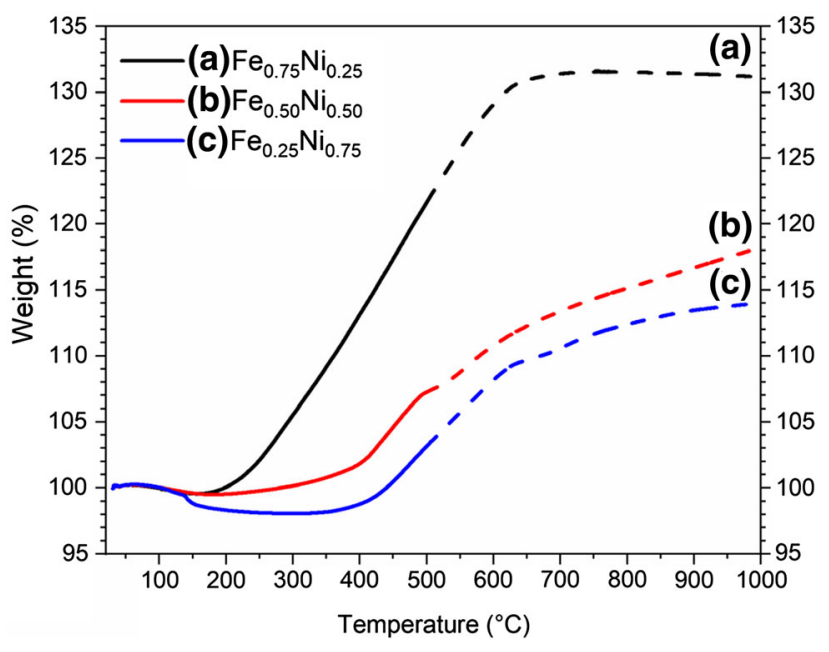

Fig. 5-Thermogravimetric curves of (a) $\mathrm{Fe}_{0.75} \mathrm{Ni}_{0.25}$, (b) $\mathrm{Fe}_{0.50} \mathrm{Ni}_{0.50}$, (c) $\mathrm{Fe}_{0.25} \mathrm{Ni}_{0.75}$ nanochains. The solid lines indicate the trend up to $500{ }^{\circ} \mathrm{C}$, whereas the dashed lines above $500{ }^{\circ} \mathrm{C}$. almost does not affect their coercivities $\left(H_{\mathrm{C}}\right)$ because only small changes of this magnetic parameter are observed. In turn, the thermal processing significantly influences the saturation magnetizations $\left(M_{\mathrm{S}}\right)$ of the investigated samples. At this point, it is important to add that the $M_{\mathrm{S}}$ values were estimated by fitting the high-field part of the measured magnetization curves to the following formula:

$$
M(B)=M_{S}\left(1-a / B-b / B^{2}\right)
$$

where $B$ is the applied magnetic field, and a and $\mathrm{b}$ are constants. In general, it is found that the $M_{\mathrm{S}}$ of as-prepared $\mathrm{Fe}-\mathrm{Ni}$ chains decreases with an increase in $\mathrm{Ni}$ content and this observation can be referred to the fact that $\mathrm{Ni}$ atoms possess lower magnetic moment than Fe atoms. ${ }^{[27,44]}$ Moreover, this observation is in agreement with the Slater-Pauling curve. ${ }^{[4]}$ The recorded value of $M_{\mathrm{S}}$ for the as-prepared $\mathrm{Fe}_{0.75} \mathrm{Ni}_{0.25}, \mathrm{Fe}_{0.75} \mathrm{Ni}_{0.25}$, and $\mathrm{Fe}_{0.75} \mathrm{Ni}_{0.25}$ chains equals about 86,61 , and $10 \mathrm{Am}^{2} \mathrm{~kg}^{-1}$, respectively. These values are, indeed, greatly lower than the highest reported $M_{\mathrm{S}}$ measured at room temperature for $\mathrm{Fe}-\mathrm{Ni}$ nanomaterials which may reach even more than $135 \mathrm{Am}^{2} \mathrm{~kg}^{-1}$. ${ }^{46-49]}$ However, it is crucial that the as-prepared $\mathrm{Fe}-\mathrm{Ni}$ chains investigated in this work are amorphous and partially contaminated as the EDS measurements suggest, whereas the highest observed $M_{\mathrm{S}}$ has been found for the well-crystalline pure $\mathrm{Fe}_{0.50} \mathrm{Ni}_{0.50}$ nanoparticles. This might cause such a big difference in the $M_{\mathrm{S}}$ values. Considering the $M_{\mathrm{S}}$ evolution of thermally treated Fe-Ni chains, two trends are clearly distinguishable. The first one concerns the $\mathrm{Fe}_{0.75} \mathrm{Ni}_{0.25}$ and $\mathrm{Fe}_{0.50} \mathrm{Ni}_{0.50}$ samples whose $M_{\mathrm{S}}$ gradually decreases with rising temperature. In turn, the second trend is associated with the $\mathrm{Fe}_{0.25} \mathrm{Ni}_{0.75}$ chains whose $M_{\mathrm{S}}$ significantly increases at $400{ }^{\circ} \mathrm{C}$ over the value measured for as-prepared sample and then it slightly decreases at $500{ }^{\circ} \mathrm{C}$. At this point, it should underline that these two $M_{\mathrm{S}}$ trends are in a good agreement with the previously discussed morphological and structural changes caused by the thermal oxidation processing and the amount of iron atoms inside the $\mathrm{Fe}-\mathrm{Ni}$ chains. Namely, according to $\mathrm{XRD}$ and $\mathrm{RS}$ results, the treatment of the $\mathrm{Fe}_{0.75} \mathrm{Ni}_{0.25}$ at

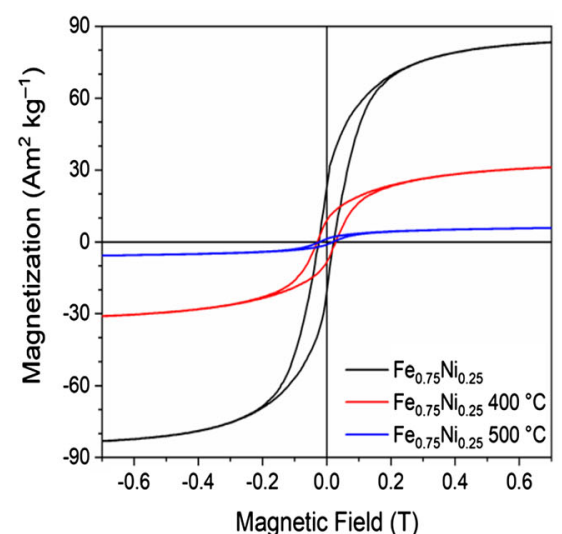

(a)

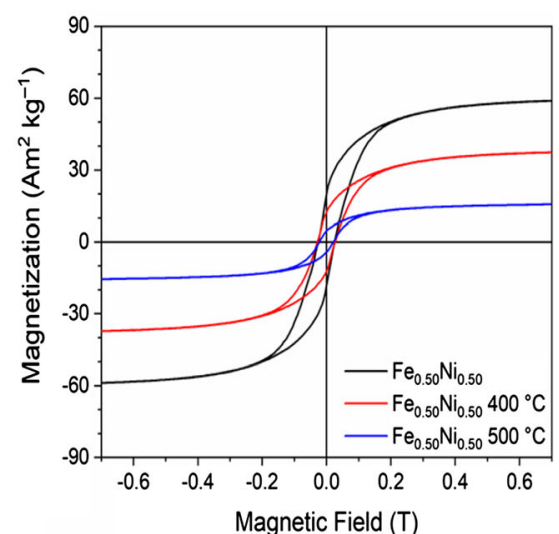

(b)

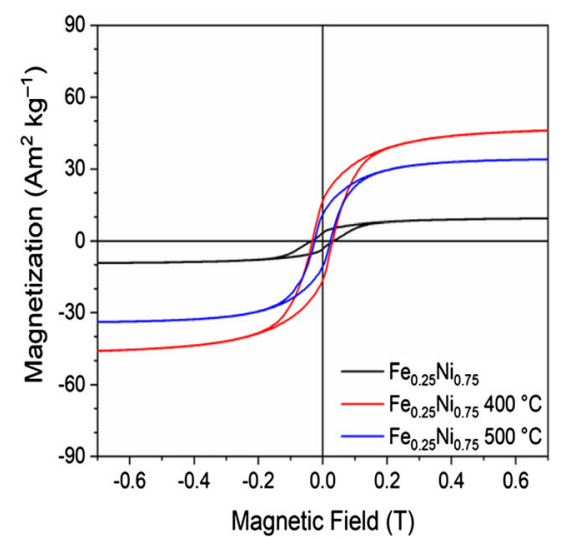

(c)

Fig. 6-Room temperature magnetic hysteresis loops of as-prepared and thermally treated (a) $\mathrm{Fe}_{0.75} \mathrm{Ni}_{0.25}$, (b) $\mathrm{Fe}_{0.50} \mathrm{Ni}_{0.50},(c) \mathrm{Fe}_{0.25} \mathrm{Ni}_{0.75}$ nanochains. 
$400{ }^{\circ} \mathrm{C}$ results in their oxidation and this causes the formation of $\mathrm{NiFe}_{2} \mathrm{O}_{4}\left(56 \mathrm{Am}^{2} \mathrm{~kg}^{-1[49]}\right), \mathrm{Fe}_{3} \mathrm{O}_{4}\left(92 \mathrm{Am}^{2}\right.$ $\left.\mathrm{kg}^{-1[28]}\right)$, and $\alpha-\mathrm{Fe}_{2} \mathrm{O}_{3}\left(0.3 \mathrm{Am}^{2} \mathrm{~kg}^{-1[28]}\right)$. The presence of these oxides, in particular substantial quantity of $\alpha-\mathrm{Fe}_{2} \mathrm{O}_{3}$, leads to the decrease of $M_{\mathrm{S}}$ of whole material. Further treatment of the $\mathrm{Fe}_{0.75} \mathrm{Ni}_{0.25}$ chains at $500{ }^{\circ} \mathrm{C}$ causes that the amount of $\alpha-\mathrm{Fe}_{2} \mathrm{O}_{3}$ increases and at the same time the $M_{\mathrm{S}}$ of $\mathrm{Fe}_{0.75} \mathrm{Ni}_{0.25} 500{ }^{\circ} \mathrm{C}$ falls down to 6 $\mathrm{Am}^{2} \mathrm{~kg}^{-1}$. Similar oxidation trend like for the $\mathrm{Fe}_{0.75} \mathrm{Ni}_{0.25}$ sample is observed for the $\mathrm{Fe}_{0.50} \mathrm{Ni}_{0.50}$ chains. Nevertheless, the presence of higher amount of nickel in the material partially inhibits the formation of $\alpha-\mathrm{Fe}_{2} \mathrm{O}_{3}$ at 400 as well as $500{ }^{\circ} \mathrm{C}$ and the following $M_{\mathrm{S}}$ decreases. Taking into account the as-prepared $\mathrm{Fe}_{0.25} \mathrm{Ni}_{0.75}$ chains, their $M_{\mathrm{S}}$ is the lowest among all as-prepared Fe-Ni samples investigated in this work. This is associated with two factors. The first one has been already mentioned before and concerns the $\mathrm{Ni}$ content in the sample. The second is related to the fact that the $\mathrm{Fe}_{0.25} \mathrm{Ni}_{0.75}$ nanochains contain the high amount of non-magnetic impurities. In turn, the oxidation of this sample is hindered due to the formation of well-covering oxide nanosheets as well as the presence of $\mathrm{Ni}_{3} \mathrm{~B}$ phase. Therefore, the oxidation of this sample at $400{ }^{\circ} \mathrm{C}$ is weaker than the competing conversion process of amorphous material into crystalline material. This, indeed, causes that the $M_{\mathrm{S}}$ values measured for the $\mathrm{Fe}_{0.25} \mathrm{Ni}_{0.75}$ $400{ }^{\circ} \mathrm{C}\left(46 \mathrm{Am}^{2} \mathrm{~kg}^{-1}\right)$ and $\mathrm{Fe}_{0.25} \mathrm{Ni}_{0.75} 500{ }^{\circ} \mathrm{C}\left(34 \mathrm{Am}^{2}\right.$ $\left.\mathrm{kg}^{-1}\right)$ are much higher than the as-prepared amorphous sample $\left(10 \mathrm{Am}^{2} \mathrm{~kg}^{-1}\right)$. At this point, it is important to note that the lower $M_{\mathrm{S}}$ value found for the sample treated at $500{ }^{\circ} \mathrm{C}$ might be associated with the continuous growth of oxide nanosheets whose impact becomes higher than in the case of the $\mathrm{Fe}_{0.25} \mathrm{Ni}_{0.75} 400{ }^{\circ} \mathrm{C}$. Nevertheless, it should be noticed that the $M_{\mathrm{S}}$ for the $\mathrm{Fe}_{0.25} \mathrm{Ni}_{0.75}$ treated at $500{ }^{\circ} \mathrm{C}$ is the highest among other samples treated at this temperature mainly due to the lack of $\alpha-\mathrm{Fe}_{2} \mathrm{O}_{3}$ formation.

\section{CONCLUSIONS}

The comprehensive studies describing the thermal oxidation at $400{ }^{\circ} \mathrm{C}$ and $500{ }^{\circ} \mathrm{C}$ in dry air of the amorphous $\mathrm{Fe}-\mathrm{Ni}$ wire-like nanochains with various iron-to-nickel compositions, which are produced in the magnetic-field-induced synthesis, are presented in this work. It is noticed that the heating treatment can lead either a conversion of amorphous material into crystalline material or its oxidation. However, the feature that mainly determines which of the abovementioned processes prevails and how the morphological, structural and magnetic properties in the investigated $\mathrm{Fe}-\mathrm{Ni}$ nanochains evolve is the amount of iron in the sample as well as the presence of impurities in the as-prepared nanostructures. Hence, it is found that the samples with the higher content of iron, i.e., the $\mathrm{Fe}_{0.75} \mathrm{Ni}_{0.25}$ and $\mathrm{Fe}_{0.50} \mathrm{Ni}_{0.50}$ nanochains, are more sensitive to oxidation than the $\mathrm{Fe}_{0.25} \mathrm{Ni}_{0.75}$ material. According to the morphological and structural investigations, the thermally treated $\mathrm{Fe}_{0.75} \mathrm{Ni}_{0.25}$ and $\mathrm{Fe}_{0.50} \mathrm{Ni}_{0.50}$ nanochains tend to be covered by the nanoparticle oxides, whereas the oxide nanosheets grow on the $\mathrm{Fe}_{0.25} \mathrm{Ni}_{0.75}$ sample. This kind of coverage constitutes a better barrier against oxidation. Moreover, the only nanochains which contain the oxidation-resistance $\mathrm{Ni}_{3} \mathrm{~B}$ phase active up to about $450{ }^{\circ} \mathrm{C}$ are those with the $\mathrm{Fe}_{0.25} \mathrm{Ni}_{0.75}$ composition. In this work, it is also shown that the specific morphologies and structures of the $\mathrm{Fe}-\mathrm{Ni}$ nanochains influence their saturation magnetizations, whereas their coercivities do not vary significantly. The highest $M_{\mathrm{S}}$ value among all thermally treated samples at $400{ }^{\circ} \mathrm{C}$ as well as $500{ }^{\circ} \mathrm{C}$ exhibits the $\mathrm{Fe}_{0.25} \mathrm{Ni}_{0.75}$ chains in which the conversion of amorphous material into crystalline material dominates over their oxidation. This confirms that the magnetic studies stay in a good agreement with the morphological and structural investigations. Finally, it should be underlined that our findings can be considered as an important source of information for the future application of the thermally treated $\mathrm{Fe}-\mathrm{Ni}$ nanochains in the sector of energy storage or catalysis.

\section{ACKNOWLEDGMENTS}

This work was supported by the National Science Centre (Poland) under Grant No. 2016/23/D/ST8/ 03268. Moreover, the authors would like to thank $\mathrm{Mr}$. Ryszard Strzałkowski from the Institute of Fundamental Technological Research, Polish Academy of Sciences (Warsaw, Poland) for his help in transmission electron microscopy investigations, Dr. Artur Małolepszy from the Faculty of Chemical and Process Engineering at the Warsaw University of Technology (Poland) for the performance of the TGA measurements, as well as Dr. Wen-An Chiou and Dr. Sz-Chian Liou from the Advanced Imaging and Microscopy Laboratory at the University of Maryland (Maryland, USA) for the performance of the EELS elemental mapping.

\section{OPEN ACCESS}

This article is licensed under a Creative Commons Attribution 4.0 International License, which permits use, sharing, adaptation, distribution and reproduction in any medium or format, as long as you give appropriate credit to the original author(s) and the source, provide a link to the Creative Commons licence, and indicate if changes were made. The images or other third party material in this article are included in the article's Creative Commons licence, unless indicated otherwise in a credit line to the material. If material is not included in the article's Creative Commons licence and your intended use is not permitted by statutory regulation or exceeds the permitted use, you will need to obtain permission directly from the copyright holder. To view a copy of this licence, visit htt $\mathrm{p}: / /$ creativecommons.org/licenses/by/4.0/.

\section{APPENDIX 1}

This Appendix contains Figures A1 and A2. 

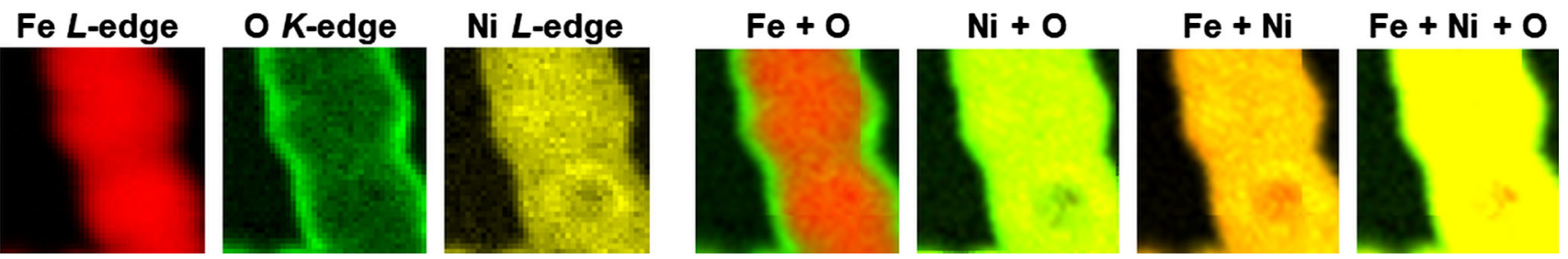

Fig. A1-EELS elemental mapping of a single $\mathrm{Fe}_{0.50} \mathrm{Ni}_{0.50}$ nanochain.
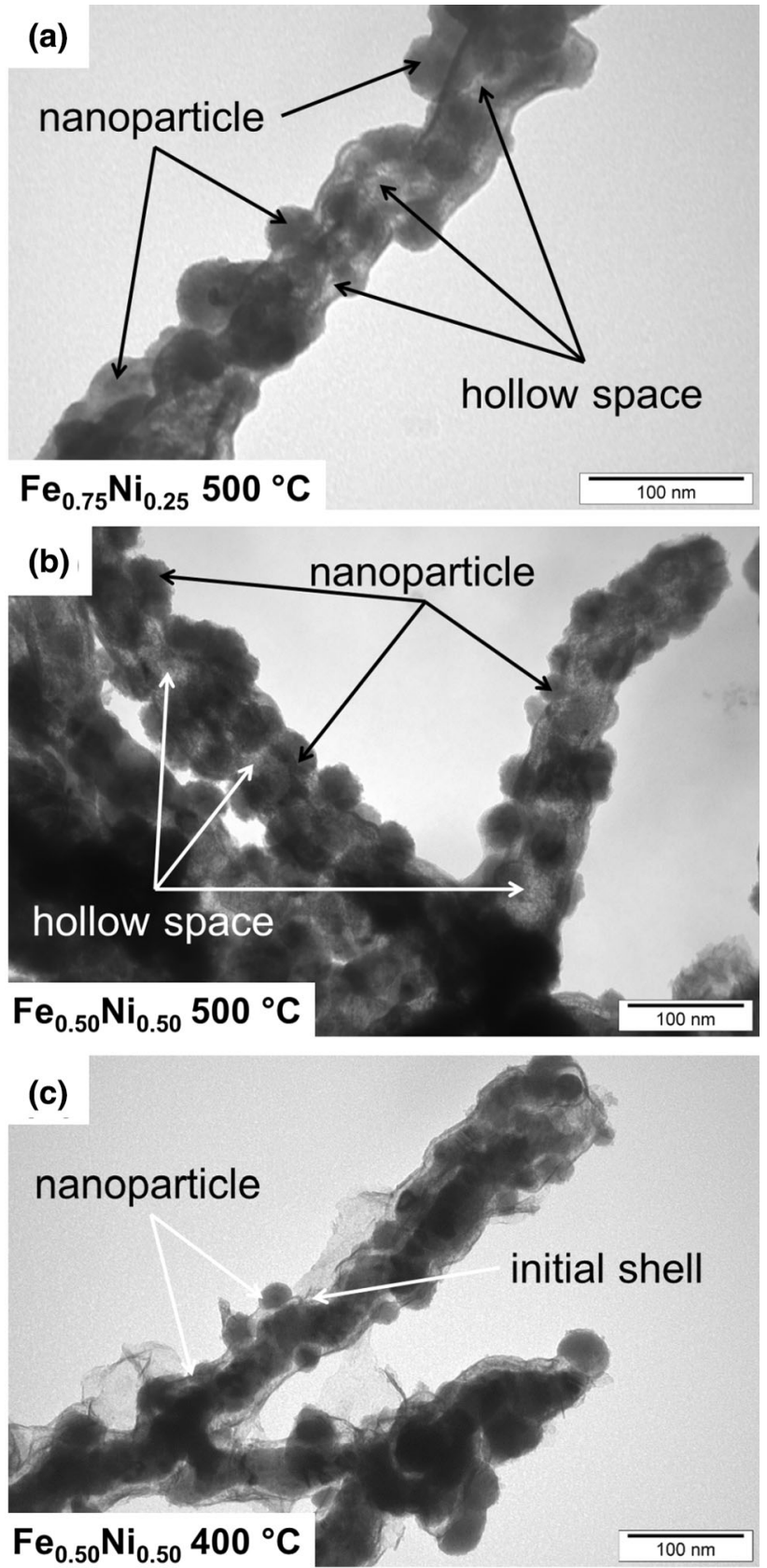

Fig. A2-TEM images of (a) $\mathrm{Fe}_{0.75} \mathrm{Ni}_{0.25}$ and (b) $\mathrm{Fe}_{0.50} \mathrm{Ni}_{0.50}$ nanochains thermally treated at $500{ }^{\circ} \mathrm{C}$. (c) TEM image of $\mathrm{Fe}_{0.50} \mathrm{Ni}_{0.50}$ nanochains thermally treated at $400{ }^{\circ} \mathrm{C}$ showing the growth of nanoparticles on the initial shell.

\section{REFERENCES}

1. B.D. Anderson and J.B. Tracy: Nanoscale, 2014, vol. 6, pp. 12195-2216.

2. A. Nel, T. Xia, L. Madler, and N. Li: Science, 2006, vol. 311, pp. $622-27$.

3. L.I. Hung, C.K. Tsung, W.Y. Huang, and P.D. Yang: $A d v$. Mater., 2010, vol. 22, pp. 1910-14.

4. J.G. Railsback, A.C. Johnston-Peck, J.W. Wang, and J.B. Tracy: ACS Nano, 2010, vol. 4, pp. 1913-20.

5. D.H. Ha, L.M. Moreau, S. Honrao, R.G. Hennig, and R.D. Robinson: J. Phys. Chem. C, 2013, vol. 117, pp. 14303-12.

6. Y.G. Sun, X.B. Zuo, S.K.R.S. Sankaranarayanan, S. Peng, B. Narayanan, and G. Kamath: Science, 2017, vol. 356, pp. 303-07.

7. M. Krajewski, K. Brzozka, W.S. Lin, H.M. Lin, M. Tokarczyk, J. Borysiuk, G. Kowalski, and D. Wasik: Phys. Chem. Chem. Phys., 2016, vol. 18, pp. 3900-09.

8. M.M. Fan, D.K. Liao, M.F.A. Aboud, I. Shakir, and Y.X. Xu: Angew. Chem.-Int. Edit., 2020, vol. 59, pp. 8247-54.

9. S.V. Lambeets, T.V. de Bocarme, D.E. Perea, and N. Kruse: $J$. Phys. Chem. Lett., 2020, vol. 11, pp. 3144-51.

10. A.A. El Mel, R. Nakamura, and C. Bittencourt: Beilstein J. Nanotechnol., 2015, vol. 6, pp. 1348-61.

11. Y.D. Yin, R.M. Rioux, C.K. Erdonmez, S. Hughes, G.A. Somorjai, and A.P. Alivisatos: Science, 2004, vol. 304, pp. 711-14.

12. R. Nakamura, J.G. Lee, H. Mori, and H. Nakajima: Philos. Mag., 2008, vol. 88, pp. 257-64.

13. C.M. Wang, D.R. Baer, L.E. Thomas, J.E. Amonette, J. Antony, Y. Qiang, and G. Duscher: J. Appl. Phys., 2005, vol. 98, art. no. 094308.

14. S. Peng and S.H. Sun: Angew. Chem.-Int. Edit., 2007, vol. 46, pp. $4155-58$.

15. C.M. Wang, D.R. Baer, J.E. Amonette, M.H. Engelhard, J. Antony, and Y. Qiang: J. Am. Chem. Soc., 2009, vol. 131, pp. 8824-32.

16. P.S. Haddad, T.R. Rocha, E.A. Souza, T.M. Martins, M. Knobel, and D. Zanchet: J. Colloid Interface Sci., 2009, vol. 339, pp. 344-50.

17. H. Khurshid, W.F. Li, V. Tzitzios, and G.C. Hadjipanayis: Nanotechnology, 2011, vol. 22, art. no. 265605.

18. R. Nakamura, G. Matsubayashi, H. Tsuchiya, S. Fujimoto, and H. Nakajima: Acta Mater., 2009, vol. 57, pp. 4261-66.

19. R. Nakamura, G. Matsubayashi, H. Tsuchiya, S. Fujimoto, and H. Nakajima: Acta Mater., 2009, vol. 57, pp. 5046-52.

20. Y. Ren, W.K. Chim, S.Y. Chiam, J.Q. Huang, C. Pi, and J.S. Pan: Adv. Funct. Mater., 2010, vol. 20, pp. 3336-42.

21. Y. Ren, S.Y. Chiam, and W.K. Chim: Nanotechnology, 2011, vol. 22, art. no. 235606.

22. J. Azevedo, M.P. Fernandez-Garcia, C. Magen, A. Mendes, J.P. Araujo, and C.T. Sousa: Sci. Rep., 2019, vol. 9, p. 11994.

23. P. Kannan, T. Maiyalagan, E. Marsili, S. Ghosh, J. Niedziolka-Jonsson, and M. Jonsson-Niedziolka: Nanoscale, 2016, vol. 8, pp. 843-55.

24. A.D. Bokare, R.C. Chikate, C.V. Rode, and K.M. Paknikar: Appl. Catal. B, 2008, vol. 79, pp. 270-78.

25. W.Q. Shen, F.E. Huggins, N. Shah, G. Jacobs, Y.G. Wang, X.B. Shi, and G.P. Huffman: Appl. Catal. A-Gen., 2008, vol. 351, pp. $102-10$.

26. Z.L. Wei, S. Yang, P.Z. Jiao, J.J. Li, H.B. Lu, Y.B. Li, X.D. He, and Y. Yuan: Mater., 2019, vol. 8, art. no. 100495.

27. M. Krajewski, M. Tokarczyk, T. Stefaniuk, H. Słomińska, A. Małolepszy, G. Kowalski, S. Lewińska, and 
A. Ślawska-Waniewska: Mater. Chem. Phys., 2020, vol. 246, art. no. 122812

28. R.M. Cornell, and U. Schwertmann: The Iron Oxides. Structure, Properties, Reactions, Occurrences and Uses, $2^{\text {nd }}$ ed.; Wiley-VCH: Weinheim, Germany, 2003, pp. 365-407.

29. A. Roy, V. Srinivas, S. Ram, J.A. De Toro, and U. Mizutani: Phys. Rev. B, 2005, vol. 71, art. no. 184443.

30. J.T. Nurmi, P.G. Tratnyek, V. Sarathy, D.R. Baer, J.E. Amonette, K. Pecher, C.M. Wang, J.C. Linehan, D.E. Matson, R.L. Penn, and M.D. Driessen: Environ. Sci. Technol., 2005, vol. 39, pp. 1221-30.

31. A.C. Johnston-Peck, J.W. Wang, and J.B. Tracy: ACS Nano, 2009, vol. 3, pp. 1077-84.

32. L. Signorini, L. Pasquini, L. Savini, R. Carboni, F. Boscherini, E. Bonetti, A. Giglia, M. Pedio, N. Mahne, and S. Nannarone: Phys. Rev. B, 2003, vol. 68, art. no. 195423.

33. Y. Wang, L.P. Li, Y.L. Zhang, X.Q. Chen, S.F. Fang, and G.S. Li: J. Phys. Chem. C, 2017, vol. 121, pp. 19467-77.

34. H. Zhou, Z.W. An, C.L. Yuan, and X.F. Luo: Ceram. Int., 2019, vol. 45 , pp. $13319-23$.

35. S.J. Oh, D.C. Cook, and H.E. Townsend: Hyperfine Interact., 1998, vol. 112, pp. 59-65.

36. A.M. Jubb and H.C. Allen: ACS Appl. Mater. Interfaces, 2010, vol. 2, pp. 2804-12.

37. L.Q. Chen, X.F. Yang, J.A. Chen, J. Liu, H. Wu, H.Q. Zhan, C.L. Liang, and M.M. Wu: Inorg. Chem., 2010, vol. 49, pp. 8411-20.

38. I. Baskaran, R.S. Kumar, T.S.N.S. Narayanan, and A. Stephen: Surf. Coat. Technol., 2006, vol. 200, pp. 6888-94.
39. S.W. Jiang, Q.Y. Zhang, Y.R. Li, Y. Zhang, X.F. Sun, and B. Jiang: J. Cryst. Growth, 2005, vol. 274, pp. 500-05.

40. N.G. Jovic, A.S. Masadeh, A.S. Kremenovic, B.V. Antic, J.L. Blanusa, N.D. Cvjeticanin, G.F. Goya, M.V. Antisari, and E.S. Bozin: J. Phys. Chem. C, 2009, vol. 113, pp. 20559-67.

41. Z. Algarni, A. Singh, and U. Philipose: Nanomaterials, 2018, vol. 8, p. 607.

42. Z.L. Schaefer, X. Ke, P. Schiffer, and R.E. Schaak: J. Phys. Chem. C, 2008, vol. 112, pp. 19846-51.

43. V. Singh, P. Banerjee, V. Srinivas, and N.H. Babu: AIP Conference Proceedings, 2011, vol. 1347, pp. 256-59.

44. M.H. Mokarian, M. Almasi-kashi, S. Alikhanzadeh-Arani, and A. Ramazani: J. Mater. Sci., 2017, vol. 52, pp. 7831-42.

45. J.M.D. Coey: Magnetism and Magnetic Materials, $1^{\text {st }}$ ed.; Cambridge University Press: Cambridge, United Kingdom, 2010, pp. 128-94.

46. B.Z. Cui, M. Marinescu, and J.F. Liu: J. Appl. Phys., 2014, vol. 115, p. 17A315.

47. X.Y. Zhang, Y. Liu, J. Li, and X.J. Yang: Mater. Res. Innovat., 2013, vol. 17, pp. 436-39.

48. N.S. Kanhe, A. Kumar, S.M. Yusuf, A.B. Nawale, S.S. Gaikwad, S.A. Raut, S.V. Bhoraskar, S.Y. Wu, A.K. Das, and V.L. Mathe: J. Alloys Compd., 2016, vol. 663, pp. 30-40.

49. M. George, A.M. John, S.S. Nair, P.A. Joy, and M.R. Anantharaman: J. Magn. Magn. Mater., 2006, vol. 302, pp. $190-95$.

Publisher's Note Springer Nature remains neutral with regard to jurisdictional claims in published maps and institutional affiliations. 